\title{
Heat Shock Protein-Based Therapeutic Strategies Against Human Immunodeficiency Virus Type I Infection
}

\author{
B.G. Brenner* and M.A. Wainberg \\ McGill AIDS Centre, Lady Davis Institute, Jewish General Hospital, and Departments of \\ Experimental Surgery and Medicine, McGill University, Montreal, Quebec, Canada
}

\begin{abstract}
Heat shock proteins (hsps) and cyclophilins (GypA) are intracellular chaperone molecules that facilitate protein folding and assembly. These proteins are selectively expressed in cells following exposure to a range of stress stimuli, including viral infection. Hsp species are highly immunogenic, eliciting humoral, cytotoxic T lymphocyte (CTL), and natural killer (NK) cell responses against viruses, tumours, and infectious diseases. This review discusses the roles of stress proteins in immunity and viral life cycles, vis-à-vis the development of $\mathrm{Hsp}$-based therapeutic strategies against human immunodeficiency virus type-1 (HIV-1) infection. Cumulative findings are cited implicating the requirement of CypA in HIV-1 replication and formation of infectious virions. Studies by our group show the upregulated expression of hsp27 and hsp70 during single-cycle HIV infections. These species redistribute to the cell surface following HIV-infection and heat stress, serving as targets for NK and antibody-dependent cellular cytotoxicity. Co-immunoprecipitation and Western blot studies show that hsp27, hsp70, and hsp78 complex with HIV-1 viral proteins intracellularly. Hsp70, hsp56, and CypA are assembled into HIV-1 virions. The ability of hsps to interact with HIV-1 viral proteins, combined with their inherent adjuvant and immunogenic properties, indicates that hsps may serve as vehicles for antigen delivery and the design of vaccines against acquired immunodeficiency syndrome. Infect. Dis. Obstet. Gynecol. 7:80-90, 1999. @1999 Wiley-Liss, Inc.
\end{abstract}

KEY WORDS

viral-host interactions; AIDS; cytotoxic T lymphocyte; NK immunity; cyclophilin A

W hile combination antiviral drug therapies have led to major advances in the management of acquired immunodeficiency syndrome (AIDS), $90 \%$ of people infected with human immunodeficiency virus (HIV) worldwide have no access to such treatments. Development of vaccines against HIV type-1 (HIV-1) remains the outstanding challenge in AIDS research. ${ }^{1,2}$ Generation of AIDS vaccines has been hampered by HIV antigenic diversity, the multiple routes and modes of HIV transmission, and ethical constraints restricting use of whole-killed or live-attenuated viruses.
To date, inactivated virus and subunit vaccines have failed to elicit impressive protective cytotoxic $\mathrm{T}$ lymphocyte (C'TL) or humoral immunity capable of neutralizing a wide spectrum of HIV-1 isolates. This has been attributed to the limited immunogenicity of viral proteins and their failure to encounter major histocompatibility complex (MHC) restriction elements required for $\mathrm{T}$ cell recognition. ${ }^{1,2}$ The immunogenic, carrier, and adjuvant properties of heat shock proteins (hsps) have been exploited as vaccine vectors to elicit protective immunity against cancers and microbial infec-

Grant sponsor: Canadian Foundation for AIDS Research (CANFAR).

*Correspondence to: Dr. Bluma G. Brenner, Lady Davis Institute, Jewish General Hospital, 3755 Cote Ste. Catherine Road, Montreal, Quebec, Canada. E-mail: mdbl@musica.mcgill.ca 
tions. This review describes the involvement of hsps in immunity and viral life cycles, vis-à-vis their potential application toward the development of Hsp-based antiviral and vaccine strategies against AIDS.

\section{HEAT SHOCK PROTEINS FUNCTION AS INTRACELLULAR MOLECULAR CHAPERONES}

The Isp family of proteins, representing 2-15\% of total cellular protein, are among the most highly conserved proteins present in procaryotic and eucaryotic organisms. ${ }^{3-5}$ Classified by apparent molecular weight (hsp70, hsp60, hsp90, hsp27), hsps were first defined as those proteins selectively synthesized following cellular exposure to temperatures $5^{\circ}$ to $10^{\circ} \mathrm{C}$ above normal. ${ }^{5}$ Hsps are now referred to as stress proteins since they are induced in response to a vast spectrum of physiological and environmental insults, including viral infection, inflammation, fever, malignant transformation, and cellular exposure to oxidizing agents, cytotoxins and anoxia. ${ }^{5,6}$

Stress proteins function as chaperone molecules having innate abilities to bind to a broad range of cellular peptides, proteins, and multimeric complexes. ${ }^{3-5}$ Constitutive Hsp subspecies, referred to as "housekeeping" proteins, direct protein folding, biogenesis, assembly, trafficking, and degradation. Inducible Hsp subspecies rapidly reprogram cellular metabolic, proliferative, and functional events in response to distinct stress stimuli.

Recent advances have revealed the mechanisms of actions of the various Hsp species. ${ }^{7} \mathrm{Hsp} 70$ homologues consist of peptide-binding and ATPase domains that stabilize protein structures in unfolded and assembly-competent states for extended periods of time. ${ }^{4,8}$ In contrast, mitochondrial hsp60 isoforms form ring-shaped oligomers wherein protein assembly to native states is facilitated. ${ }^{4}$ Hsp90 species associate with cellular tyrosine kinases, transcription factors, and glucocorticoid receptors, playing suppressor regulatory roles. ${ }^{5,7,9} \mathrm{Hsp} 27$ proteins suppress protein aggregation, protect against actin polymerization, and represent end components of stress and cytokine kinase (MAPK) cascades. ${ }^{10-13}$ Binding of the ubiquitin species targets protein complexes for degradation. ${ }^{3,5}$ Immunophilins, including cyclophilins and FK binding proteins (FKBPs), catalyze cis/ trans isomerization of peptidyl-prolyl bonds, key rate-limiting steps in protein folding. ${ }^{3}$

\section{HSPS PLAY CENTRAL ROLES IN IMMUNE RESPONSE}

Besides their biological roles as chaperonins and stress proteins, hsps are extraordinarily immunogenic. Stress proteins have been implicated in host immunity to tumours and viral and microbial infections. ${ }^{14-17}$ Select Hsp species represent major targets for humoral (B cell) and cell-mediated $(\alpha \beta$ and $\gamma \delta \mathrm{T}$, natural killer [NK], and lymphokineactivated $[\mathrm{LAK}]$ cell) immunity. ${ }^{14-27}$ The immunogenic properties of hsps have led to considerable interest in their application in vaccine strategies. ${ }^{16,17}$ Vaccinations with Hsp-peptide complexes have been shown to augment CTL, $\gamma \delta \mathrm{T}, \mathrm{NK}$, and LAK cell responses against tumour and viral antigens. ${ }^{16-27}$ Reasons why highly conserved stress proteins play such a prominent role in immunity are still not well understood. Based on in vitro and in vivo studies, several distinct mechanisms wherein hsps induce viral and tumour immunity have been identified.

\section{Stress Proteins Can Act as Classic Antigens}

Major portions of the immune repertoire can recognize microbial Hsp and autologous Hsp determinants generated following stress, viral infection, or malignant transformation. ${ }^{14-17} \mathrm{Hsp} 70$ and hsp60 are the predominant antigenic species recognized in many microbial infections, including malaria, leprosy, and tuberculosis. Analysis of immune responses to mycobacterial infections indicates that 20-30\% of the overall CTL and T cell repertoire are directed against Hsp moieties. ${ }^{16,21}$ Indeed, prophylactic vaccinations with microbial hsps have been shown to generate significant protective immunity against bacterial, fungal, and mycobacterial infections. ${ }^{14-17}$

Stress proteins are impressively upregulated by both host and pathogen at sites of infection, enhancing Hsp-directed responses. That highly conserved hsps serve as classic foreign antigens is substantiated by correlative links between immunity to foreign microbial hsps and the emergence of Hsp autoimmune reactions in rheumatoid arthritis, systemic lupus, Graves disease, diabetes mellitus, inflammatory diseases, and neurological aging. ${ }^{28}$ Autoimmune pathology has even been postulated 


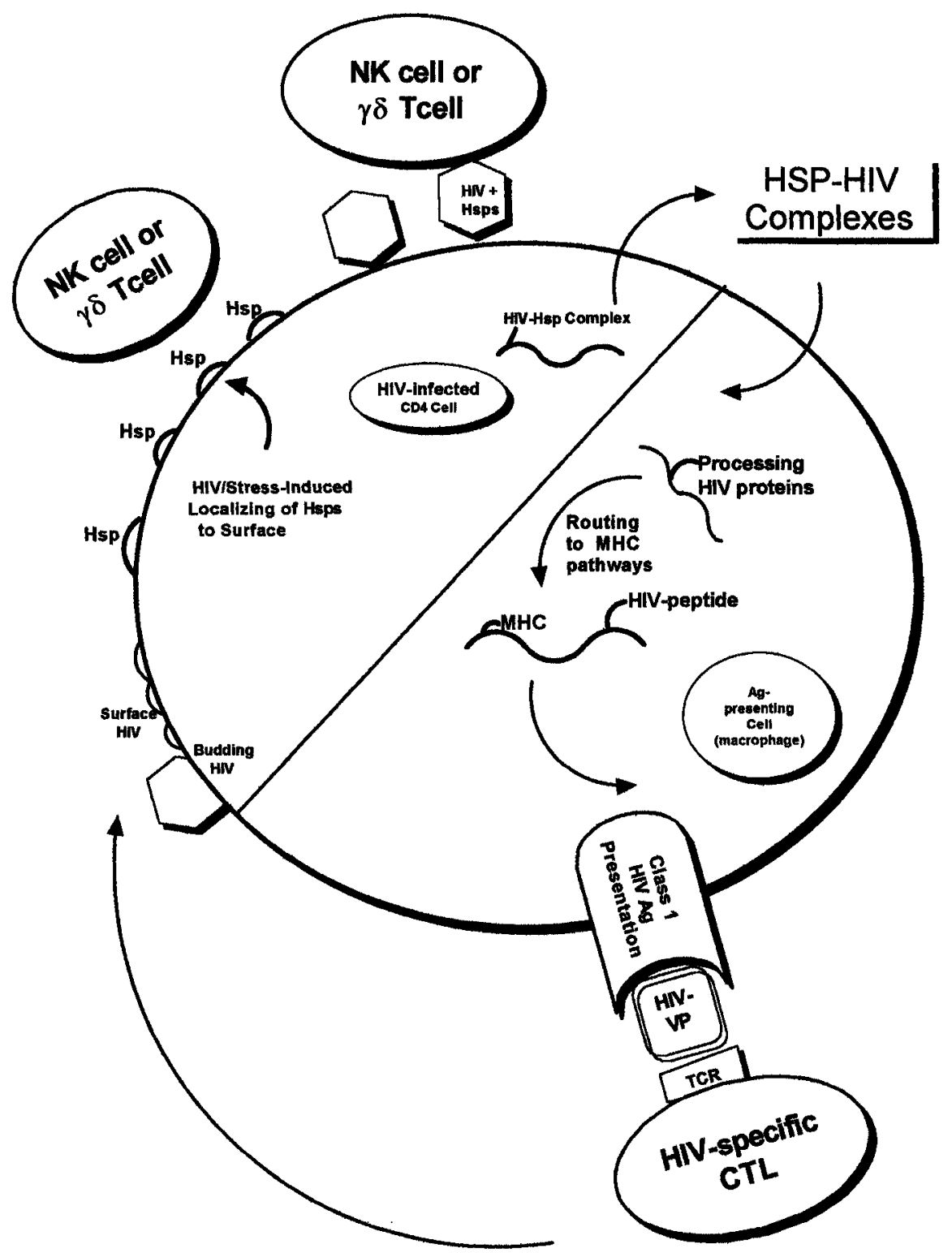

Fig. I. Several possible mechanisms wherein hsps may elicit antiviral immunity. 1) Hsps may redistribute to the cell surface in virally-infected cells; 2) Hsp-viral complexes (HIV-VP) may be present on the cell surface; and 3) antigen (Ag)-presenting cells, including macrophages and dendritic cells may incorporate viral peptide-Hsp complexes allowing viral peptides to be expressed in the context of MHC class-I determinants to T-cell receptors (TCR) on CTLs.

to contribute to the ongoing clearance of stressed or infected CD4 cells in AIDS (Fig. 1). ${ }^{23,24}$

\section{Stress Proteins Can Redistribute to Cell Surface Membranes Following Infection or Transformation}

Cytosolic stress proteins, including hsp27 and hsp70, have been shown to relocate to the plasma membrane in transformed, virally-infected or heatstressed cells. ${ }^{22-26}$ The de novo distribution of hsps on the plasma membrane specifically targets tumour and HIV-infected cells for elimination by antibody-dependent cellular cytotoxicity (ADCC), NK, LAK and $\alpha \beta$ T cell-mediated immunity (Fig. 1). ${ }^{22-26}$

\section{Hsps Can Serve as Adjuvants and Vaccine Vectors}

Hsps can indirectly enhance immune responses to tumours and viral antigens because of their adju- 
vant properties. The immunostimulatory properties of the mycobacterial-derived constituents in Freund's adjuvant and Bacillus Calmette-Guérin (BCG) have been attributed to and/or mimicked by adjuvant-free hsp60 and hsp70 carrier proteins. ${ }^{16,17}$ The strong adjuvant effects of hsps when conjugated to peptides and oligosaccharides have been exploited to stimulate immune responses in a variety of infections. ${ }^{16,17,29-32}$ Similarly, BCG may be useful as live vaccine vector for HIV-1 constituents. ${ }^{29,30}$ Mice that have been vaccinated with fused hsp70-HIVp24 complex elicit humoral and CTL immune responses to the HIV-1 capsid proteins for over 1 year, with no corresponding immunity evoked in mice injected with soluble p 24 protein. ${ }^{31}$

\section{Stress Proteins Can Be Integrally Involved in Antigen Presentation}

Soluble proteins are weakly immunogenic due to their failure to effectively elicit MHC-restricted CTL responses. This has been attributed to the failure of soluble proteins to be incorporated by professional antigen-presenting cells, such as macrophages. In contrast, associations of tumour or viral proteins with hsp70, gp96 or hsp90 moieties stimulate antitumour and antiviral CTL immunity (Fig. 1). ${ }^{19,31-36} \mathrm{It}$ appears that the interactions of hsps with tumour or viral antigens allow for their effective uptake into professional antigen processing cells, such as macrophages, allowing for the processing of antigenic complexes along the $\mathrm{MHC}$ class-1 pathway for CTL presentation.

The precise role of hsps is unclear but has been referred to as Hsp-mediated "cross-priming," insofar as the CTL responses are directed against the peptides bound to the hsps and not the hsps themselves. ${ }^{33,34}$ Hsps appear to serve as antigenic carriers that route exogenous proteins into macrophages, wherein proteins are cleaved and translocated for class 1 MHC presentation. Hsp70, gp96, and hsp90 subspecies, like MHC determinants, can chaperone tumour and viral peptides of 400-2000 Da intracellularly. ${ }^{37} \mathrm{Hsp} 70$ and hsp 96 moieties are also implicated in the folding of MHC molecules. ${ }^{33-37}$ Indeed, hsp70 species show considerable homology with MHC class 1 molecules, and hsp70 genes have been localized to the MHC gene complex. ${ }^{34-38}$ This has led to a postulated role of Hsp moieties in peptide charging of MHC mol- ecules. ${ }^{33-37,39}$ Immunizations of animals with hsp70 and hsp90 complexes from virally-infected or tumour cells elicit protective antiviral and tumour-specific CTLs and memory cells. ${ }^{35-37,39-46}$

\section{STRESS PROTEINS IN THE IMMUNOTHERAPY OF CANCERS, INFECTIOUS DISEASES AND AIDS}

The antigenic, adjuvant, and carrier properties of hsps have heralded their potential application as "magic bullets" in cancer and viral immunotherapy. ${ }^{44-47}$ Hsp-tumour conjugates and Hsp complexes isolated from cancer cells have been demonstrated to produce tumour-specific CTL responses and protective antitumour immunity in animals. ${ }^{35-37,39-40,42-47}$ It has been postulated that vaccination with Hsp-peptide complexes purified from tumour cells will 1) maximize the tumour antigenic repertoire in immunized cancer patients; 2 ) circumvent the requirement to identify and purify unique tumour antigens; 3) eliminate inherent problems of MHC disparity among individuals; and 4) obviate the necessity for adjuvants to stimulate immunity. Although still at the formative stage, Hsp-peptide complexes have been heralded as novel approaches to customize cancer therapeutic vaccines from patients' own cancer cells. Phase 1 clinical trials are currently in progress. ${ }^{44-47}$

Cell culture and animal model systems have shown that Hsp complexes purified from virallyinfected cells can generate viral-specific CTLs and/or protective immunity against simian virus 40 , influenza, vesicular stomatitis, and lymphocytic choriomeningitis viral infections. ${ }^{35,41,44}$ Young et al. are currently exploring the applicability of HIVp24-hsp70 conjugates as vaccines in monkeys. ${ }^{16,30-32,36}$ Given the vital necessity for an AIDS vaccine, establishing the roles of hsps in HIV replication, assembly, and immunity are warranted.

\section{THE SPECIFIC ROLE OF STRESS PROTEIN SUBSPECIES IN HIV-I VIRAL REPLICATION}

Several lines of investigation have implicated stress proteins in viral-host interactions in many DNA and RNA virus infections. $5,20,24,48,49$ These include demonstrations that:

1) Stress protein expression correlates with levels of viral expression and replication. 


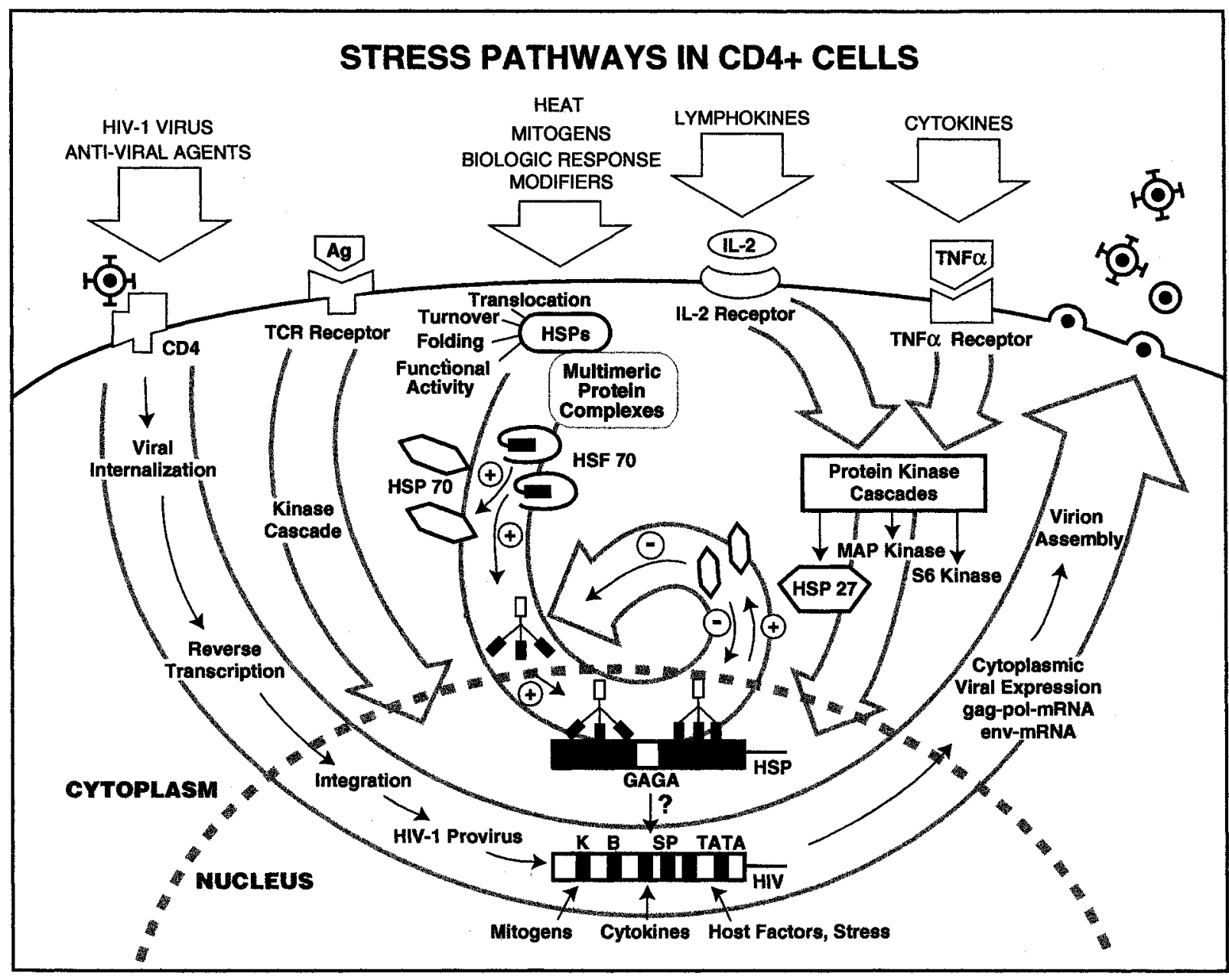

Fig. 2. Potential interactions between stress protein and HIV-I viral pathways in HIV-I infected CD4 cell lymphocytes. TCR $=\mathrm{T}$-cell receptor; HSF $70=$ heat shock factor 70 .

2) Stress proteins facilitate rate-limiting steps in viral replication.

3) Hsps affect the folding and assembly of viral intermediates and virions.

4) Incorporation of stress proteins into viruses determines virion infectivity.

5) 'The presence of stress proteins on the cell surface elicits antiviral immunity.

It is to be expected that the HIV-1 virus may have an obligatory requirement for host stress proteins to facilitate their replication and assembly in CD4 cells. Studies showing involvement of stress proteins in the HIV-1 life cycle will be described, vis$\grave{a}$-vis the potential application of hsps in AIDS antiviral strategies.

\section{MODULATION OF HSP27 AND HSP70 EXPRESSION IN CD4+ CELLS CONSEQUENT TO HIV-I INFECTION}

Viral-induced activations of specific stress genes have been described during latent, productive, and lytic phases of infection with DNA and RNA viruses. ${ }^{5,20,24,48,49}$ It has been shown in many systems that induction of hsp70 and hsp 90 genes are among the earliest changes in cellular gene expression following viral infection. ${ }^{20,48,50}$ Induced expressions of select hsp70 moieties with different viruses suggest viral-dependent hsp70 gene activation. ${ }^{20,50}$

The HIV-1 virus differentially infects CD4 cells of lymphocytic and monocytic origin through the CD4 and chemokine surface receptors (Fig. 2). Studies in our laboratory have used Northern and Western blot analysis to chart changes in levels of 


\section{Presence of Hsp70 in HIV-1 virions relative to p24 and Pr55gag capsid moieties}

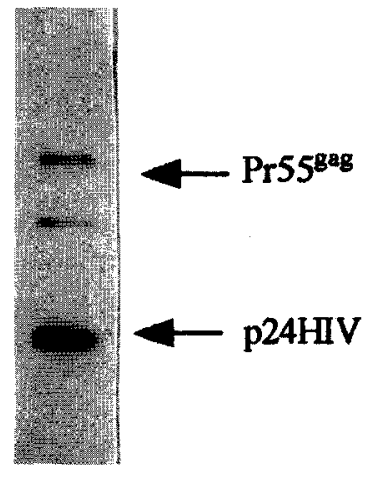

\section{A. Blot A probed with $\alpha p 24$ antibodies}

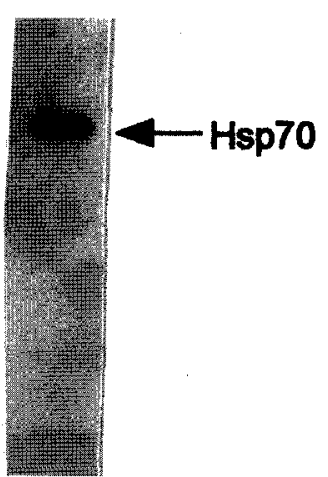
B. Blot B probed with $\alpha$ Hsp70 antibodies

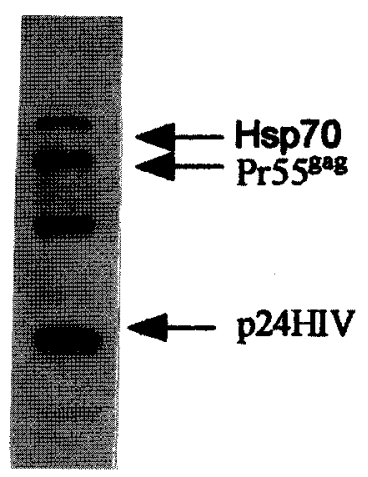

\section{Blot A reprobed with $\alpha$ Hsp70 antibodies}

Fig. 3. Western blot analysis showing the presence of A) HIV-I p24 reactive capsid determinants in virion particles; B) hsp70 in purified HIV-I virions; and C) levels of hsp70 relative to HIV-I gag proteins.

Hsp mRNA and protein expression in CD4 cells during single-cycle HIV-1 infections. ${ }^{51}$ Acute HIV infection of H9, CEM, Jurkat and MT-2 lymphocytic cell lines leads to eight- to 20 -fold increases in levels of hsp27 and hsp70 mRNA and protein expression at early stages of infection (1-6 hr) subsequent to viral penetration but prior to viral mRNA synthesis that occurs $36-48 \mathrm{hr}$ postinfection..$^{51,52}$ Initial increases in hsp27 and hsp70 are downregulated during productive stages of viral synthesis. Elevations in levels of these Hsp species recur at lytic endstages of infection, concomitant to virion release and cytolysis. Induction of hsp27 and hsp70 synthesis are viral dose-related and abrogated by HIV-1 neutralizing antibodies, CD4 antibodies or inactivation of virus. In direct contrast to that observed with hsp27 and hsp70 species, levels of hsp60 and hsp90 mRNA and protein moieties remain unaltered throughout the course of HIV infection. Two-dimensional gel electrophoresis reveals that the hsp70 isoforms induced following HIV infection show distinct isoelectric mobilities from constitutive and heat-inducible hsp70 species.

Studies by a number of investigators have assessed correlative changes in levels of HIV-1 and Hsp gene and protein expression in infected cells. Somewhat contradictory results have been obtained. Stress stimuli, including heat, tumor necrosis factor- $\alpha$ (TNF- $\alpha)$, and interleukin 2 (IL-2), can induce in Hsp and viral gene transcription with similar kinetics. ${ }^{53-55}$ However, heat shock and TNF- $\alpha$ induce states of cellular latency, wherein enhanced Hsp synthesis markedly inhibits overall levels of viral mRNA and protein synthesis. ${ }^{56}$,unpublished results Cyclopentenone prostaglandins (prostaglandins $\mathrm{A}$ and $\mathrm{J}$ ) have also been known to block human $\mathrm{T}$-cell lymphotropic virus (HTLV-1) and HIV-1 viral replication through induction of an hsp70 stress response. ${ }^{57-61}$ Hyperthermia at $3-4^{\circ} \mathrm{C}$ above physiological range can block HIV-1 viral replication in vivo and has led to the postulated benefits of localized or systemic hyperthermia in HIV infection. ${ }^{20,62}$

\section{HSP27 AND HSP70 EXPRESSION ON THE SURFACE OF HIV-I INFECTED CELLS}

Apart from their increased intracellular levels of expression during infection, significant amounts of hsp27 and hsp70 have been shown to redistribute to the cell surface of $\mathrm{CD} 4+$ cell lines following heat stress or HIV-1 infection. ${ }^{23,24}$ The enhanced expression of HIV-1 on the cell surface contribute to the enhanced susceptibility of HIV-infected cell lines to NK, LAK, and HIV-specific ADCC cell-mediated cytotoxicity when compared to that observed for their uninfected counterparts (Fig. 1). 23,24,63,64,unpublished results 


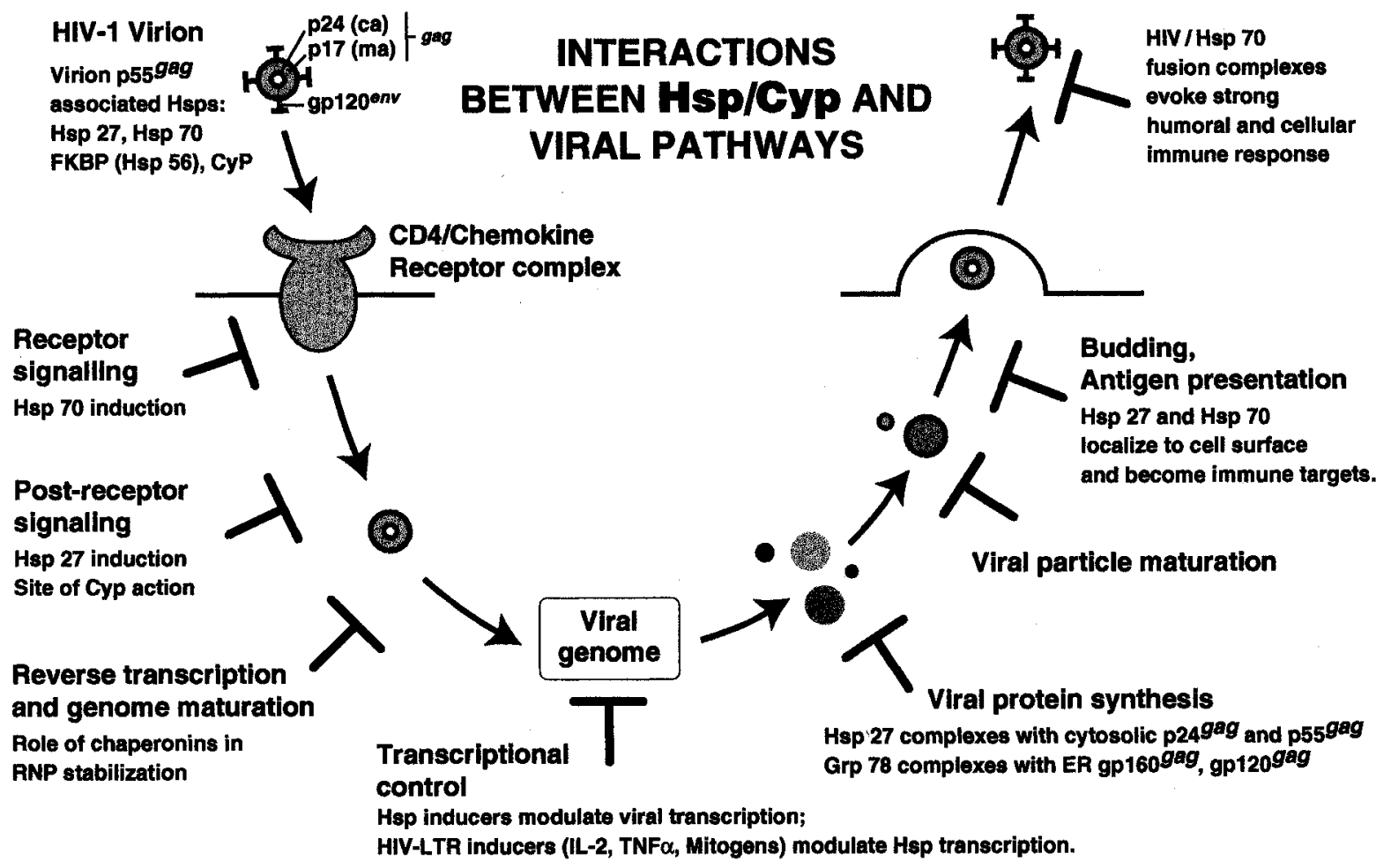

Fig. 4. Cumulative information showing sites of interaction of hsps and cyclophilins (Cyp) with HIV-I viral proteins and virions. RNP = ribonucleoprotein; HIV-LTR = HIV-long terminal repeat.

This enhanced susceptibility of HIV-infected lymphocytes to natural immunity may contribute to antiviral immunity in vivo. However, it should be noted that basal and IL-2 inducible NK cellmediated cytotoxicity has been shown to decline progressively with advancing HIV disease. ${ }^{63-68}$ Indeed, inducible NK cell function is among the most sensitive functional correlates of immunological dysfunction in HIV infection.

\section{INTERACTIONS OF STRESS PROTEINS WITH HIV VIRAL PROTEINS AND VIRION PARTICLES}

The association of stress proteins with viral intermediates can facilitate their folding, assembly, and morphogenesis with a direct impact on rates of viral production and infectivity. Biosynthetic assembly of the HIV-1 envelope protein glycoprotein 160 (gp160) to its native state has been shown to involve the cellular chaperonins grp78-BiP (the endoplasmic reticulum hsp70 species) and calreticulin. ${ }^{69,70}$ These stress proteins bind in a specific and transient fashion and are released only after the envelope protein assumes its native conformation.
Our laboratory has used reciprocal co-immunoprecipitation approaches to show that hsp27 and HIV-1 capsid (gag) moieties form intracellular complexes (manuscript in preparation). Similarly, hsp 70 can be shown to be complexed with HIV-1 gag precursor moieties that can be precipitated with HIV-1 p24 antibodies.

The strongest evidence that stress proteins are fundamentally required for HIV-1 virion assembly and infectivity come from studies with the chaperonin, cyclophilin (CypA). CypA has been shown to specifically interact with the HIV-1 capsid (gag) protein and is essential for the production of infectious HIV-1 virions. ${ }^{49,71-73}$ CypA weakens gagcapsid strips and promotes capsid disassembly following HIV-1 penetration into cells. ${ }^{49,74}$ Studies with cyclosporins show that the failure to incorporate CypA in HIV-1 virions abrogates the infectivity of viruses. ${ }^{49,75}$ CypA is found to associate with some HIV-1 clades and not others and is generally absent in simian immunodeficiency viruses. ${ }^{76} \mathrm{Lev}-$ els of HIV-1 virus infectivity and CypA in virions are directly related to cellular levels of CypA expression. ${ }^{77,78}$ Recent studies indicate that CypA 
and FKBP can also bind to the V3 loop of HIV envelope (env) protein. ${ }^{79}$ Indeed, HIV-1 infection of peripheral blood lymphocytes can be blocked by an excess CypA or neutralizing antibodies to CypA. ${ }^{80}$

Studies in our laboratory have determined that select Hsp subspecies also associate with HIV-1 virions purified from HIVIIIb-infected (CEM, H9, Jurkat) (manuscript in preparation). Hsp70 (inducible) proteins are specifically incorporated into HIV-1 virions (Fig. 3). These findings contradict earlier studies by Bartz et al., who found hsp60 but not hsp70 moieties in polyethylene glycol precipitated viruses isolated from HIV-1 and SIV virions. ${ }^{81}$ Using subtilisin extraction procedures, we show that hsp70 is retained in virions while contaminating microvesicular elements are degraded. Thus, hsp 60 may be associated with HIV- 1 virion assembly intermediates but are not present in purified virions. ${ }^{81}$

Like that reported for CypA, we show hsp70 to be notably absent in SIV virions. We have also isolated capsid virus-like particles from COS-7 cells transfected with vectors producing Pr55 or Pr160 gag capsid precursor proteins. Hsp70, FKBPs (hsp56), and CypA are found to be present in gagcapsid particles.

\section{SUMMARY}

Taken together, these results show correlative links in stress protein and HIV replicative pathways in CD4 cells (Fig. 2, Fig. 4). Infection with HIV-1 viruses induces a stress response and stress agonists, such as heat, IL-2 and TNF- $\alpha$, affect HIV-1 replicative events. Hsp27 and hsp70 stress pathways are induced in CD4 cells concomitant to HIV-1 infection, and these species can distribute on the cell surface of infected cells. Cumulative evidence indicates that hsp70, hsp78, calreticulin, FKBPs, and CypA are among those stress protein subspecies found to be associated with HIV-1 viral proteins or virions.

Having documented existent interactions between stress proteins and HIV-1 viral constituents, it is feasible that Hsp-viral complexes may offer a number of unique vaccine approaches against AIDS. The inherent adjuvant properties of hsps may enhance the immunogenicity of HIV-1 proteins and allow exogenously-presented HIV-1 viral proteins to be processed for CTL presenta- tion. ${ }^{35,41,44,82}$ Specific HIV subunit vaccines conjugated to hsp70, hsp78, and gp96 proteins may enhance CTL immunity. Immunization with heterogeneous mixtures of Hsp-viral antigenic species may prevent the emergence of CTL escape mutants. Hsp-viral complexes may customize immunogens in distinct HIV-1 infected populations.

Preliminary clinical trials of a number of Hspbased vaccines against cancer and microbial infections are ongoing. Phase 1 trials for the use of Hspp24gag fusion complexes as an AIDS vaccine are in place. ${ }^{16,31}$ Given the difficulty, to date, in generating an AIDS vaccine, investigations into the potential use of Hsp-based AIDS vaccines are warranted.

\section{REFERENCES}

1. Letvin NL. Progress in the development of an HIV-1 vaccine. Science 1998;280:1875-1880.

2. Steinman RM, Germain RN. Antigen presentation and related immunological aspects of $H I V-1$ vaccines. AIDS 1998;12:S97-S112.

3. Gething MJ, Sambrook J. Protein folding in the cell. Nature 1992;355:33-45.

4. Craig EA, Weissmann JA, Horwich AL. Heat shock proteins and molecular chaperones: Mediators of protein conformation and turnover in the cell. Cell 1994;78:365372.

5. Morimoto RI, Tissières A, Georgopoulos C. Progress and perspectives on the biology of heat shock proteins and molecular chaperones. In Morimoto RI, Tissières A, Georgopoulos C (eds): The Biology of Heat Shock Proteins and Molecular Chaperones. Cold Spring Harbor, NY: Cold Spring Harbor Laboratory Press, 1994, pp $1-30$.

6. Morimoto RI. Cells in stress: transcriptional activation of heat shock genes. Science 1993;259:1409-1410.

7. Craig EA, Gambill BD, Nelson RJ. Heat shock proteins: Molecular chaperones of protein biogenesis. Microbiol Rev 1993;57:402-414.

8. James P, Pfund C, Craig EA. Functional specificity among hsp70 molecular chaperones. Science 1997;275: 387-391.

9. Rutherford SL, Zuker CS. Protein folding and the regulation of signalling pathways. Cell 1994;79:1129-1132.

10. Arrigo AP, Landry J. Expression and function of low molecular weight heat shock proteins. In Morimoto RI, Tissières A, Georgopoulos C (eds): The Biology of Heat Shock Proteins and Molecular Chaperones. Cold Spring Harbor: Cold Spring Harbor Laboratory Press, 1994, pp 335-373.

11. Mehlen P, Preville X, Charyron P, Briolay J, Klemenz R, Arrigo AP. Constitutive expression of human hsp27, Drosophila hsp27, or human alpha B-crystallin confers 
resistance to TNF- and oxidative stress-induced cytotoxicity in stable transfected murine L929 fibroblasts. J Immunol 1995;154:363-374.

12. Rouse J, Cohen P, Trigon S, et al. A novel kinase cascade triggered by chemical stress and heat shock which stimulates MAP kinase-activated protein kinase-2 and phosphorylation of the small heat shock proteins. Cell 1994;78:1027-1037.

13. Freshney NW, Rawlinson L, Guesden F, et al. Interleukin-1 activates a novel protein cascade which results in phosphorylation of hsp27. Cell 1994;78:1039-1049.

14. Dubois P. Heat shock proteins and immunity. Res Immunol 1989;140:653-659.

15. DeNagel DC, Pierce SR. Heat shock proteins in immune response. Crit Rev Immunol 1993;13:71-81.

16. Mizzen L. Immune responses to stress proteins: Applications to infectious disease and cancer. Biotechnology 1998;10:173-189.

17. Newport GR. Heat shock proteins as vaccine candidates. Semin Immunol 1991;3:17-24.

18. Boltzer G, Li G, Issels RD, Multhoff G. Definition of extracellular localized epitopes of hsp70 involved in an NK immune response. Cell Stress Chaperones 1998;3: 6-11.

19. Srivastava PK. Heat shock proteins in immune response to cancer: The fourth paradigm. Experientia 1994;50: 1054-1060.

20. Santoro MG. Heat shock proteins and virus replication: hsp70s as mediators of antiviral effects of prostaglandins. Experientia 1994;50:1039-1047.

21. Born W, Happ M, Dallas A, et al. Recognition of heat shock proteins and cell function. Immunol Today 1990; 11:40-43.

22. Multhoff G, Boltzer C, Wiesnet M, et al. A stressinducible $72 \mathrm{kda}$ heat-shock protein (HSP72) is expressed on the surface of human tumor cells, but not on normal cells. Int J Cancer 1995;61:272-275.

23. DiCesare S, Poccia F, Mastino A, Colizzi V. Surface expressed heat-shock proteins by stressed or human immunodeficiency virus (HIV)-infected lymphoid cells represent the target for antibody-dependent cellular cytotoxicity. Immunology 1992;76:341-343.

24. Poccia F, Placido R, Mancino G, et al. Expression of heat-shock proteins in HIV-1 infection. In Montagnier L, Gougeon ML (eds): New Concepts in AIDS pathogenesis. New York: Marcel Dekker Inc, 1993, pp 195218.

25. Multhoff G, Botzler G, Jennen L, Schmidt J, Ellwart J, Issels R. Heat shock protein on tumor cells: A recognition structure for natural killer cells. J Immunol 1997; 158:4341-4350.

26. Multhoff G, Boltzer C, Wiesnet M, Eissner G, Issels R. CD3 - large granular lymphocytes recognize a heatinducible immunogenic determinant associated with the $72-\mathrm{kD}$ heat shock protein on human sarcoma cells. Blood 1995;86:1374-1382.

27. Fujeida S, Noda I, Saito H, Hoshino T, Yagita M. Heat shock enhances the susceptibility of tumor cells to lysis by lymphokine activated killer cells. Arch Otolaryngol Head Neck Surg 1995;121:1009-1014.

28. van Eden W, van der Zee R, Paul AGA, et al. Do heat shock proteins control the balance of ' $T$ cell regulation in inflammatory diseases. Immunol Today 1998;19:303307.

29. Ikonomidis G, Paterson Y, Kos FJ, Portnoy DA. Delivery of a viral antigen to class 1 processing and presentation pathways by Listeria monocytogenes. J Exp Med 1994;180:2209-2218.

30. Aldovini A, Young RA. Humoral and cell-mediated immune responses to live recombinant BCG-HIV vaccines. Nature 1991;351:479-482.

31. Suzue K, Young RA. Adjuvant-free hsp70 fusion protein system elicits humoral and cellular immune responses to HIV-1 p24. J Immunol 1996;156:873-879.

32. Young RA, Suzue K. Heat shock proteins as immunological carriers and vaccines. EXS 1996;77:451-465.

33. Li Z, Srivastava KI. A critical contemplation of the role of heat shock proteins in transfer of antigenic peptides during antigen presentation. Behring Inst Mitt 1994;94: 37-47.

34. Pierce SK. Molecular chaperones in the processing and presentation of antigen to helper cells. Experientia 1994;50:1026-1030.

35. Suto R, Srivastava PK. A mechanism for the specific immunogenicity of heat shock protein-chaperoned peptides. Science 1995;269:1585-1588.

36. Suzue K, Zhou X, Eisen HN, Young RA. Heat shock proteins as vehicles for antigen delivery into the major histocompatibility complex class 1 presentation pathway. Proc Natl Acad Sci USA 1997;94;13146-13151.

37. Srivastava PK. Peptide-binding heat shock proteins in the endoplasmic reticulum: role in immune response to cancer and antigen presentation. Adv Cancer Res 1993; 62:153-177.

38. Sargent CA, Dunham I, Trowsdale J, Campbell RD Human major histocompatibility complex contains genes for the major heat shock protein HSP70. Proc Natl Acad Sci USA 1989;86:1968-1972.

39. Srivastava PK. Purification of heat shock protein peptide complexes for use in vaccination against cancers and intracellular pathogens. Methods 1997;12:165-171.

40. Tamara Y, Peng P, Liu K, Daou M, Srivastava PK. Immunotherapy of tumors with autologous tumor-derived heat shock protein preparations. Science 1997;278:117120.

41. Ciupitu AM, Petersson M, O’Donnell CL, Williams K, Jindal S, Kiessling R, Welsh RM. Immunization with a lymphocytic choriomeningitis virus peptide mixed with heat shock protein 70 results in protective antiviral immunity and specific cytotoxic T lymphocytes. J Exp Med 1998;187:685-691.

42. Li Z. Priming of $T$ cells by heat shock protein-peptide complexes as the basis of tumor vaccines. Semin Immunol 1997;9:315-322.

43. Blachere NE, Li Z, Chandawarkar RY, et al. Heat shock protein-peptide complexes, reconstituted in vivo, elicit 
peptide-specific cytotoxic $\mathrm{T}$ lymphocyte response and tumor immunity. J Exp Med 1997;186:1315-1322.

44. Heikema A, Agsteribbe E, Wilschut J, Huckriede A. Generation of heat shock protein-based vaccines by intracellular loading of gp96 with antigenic peptides. Immunol Lett 1997;57:69-74.

45. Srivastava PK, DeLeo AB, Old LJ. Tumour rejection antigens of chemically induced tumours of inbred mice. Proc Natl Acad Sci USA 1986;83:3407-3411.

46. Maxwell CA, Durrant LG, Scholefield JH. Colorectal cancer vaccines. Brit J Surg 1998;85:149-154.

47. Featherstone $\mathrm{C}$. Chaperoning tumour antigens into the immune system. Lancet 1996;348:1438.

48. Santoro MG. Viral infection. EXS 1996;77:337-357.

49. Luban J. Absconding with the chaperone: essential cyclophilin-Gag interaction in HIV-1 chaperones. Cell 1996;87:1157-1159.

50. Phillips B, Abravya K, Morimoto RI. Analysis of the specificity and mechanism of transcriptional activation of the human hsp70 gene during infection by DNA viruses. J Virol 1991;65:5680-5692.

51. Wainberg Z, Oliveira M, Lerner S, Tao Y, Brenner BG. Modulation of stress protein (hsp27 and hsp70) expression in CD4+ lymphocytic cells following acute infection with human immunodeficiency virus type 1 . Virology 1997;233:364-373.

52. Furlini G, Vignoli M, Le MC, et al. Human immunodeficiency virus type 1 interaction with the membrane of CD4+ cells induces the synthesis and nuclear translocation of 70K heat shock protein. J Gen Virol 1994;75: 193-199.

53. Geelen JL, Minnaar RP, Boom R, van der Noordaa J, Goudsmit J. Heat-shock induction of the human immunodeficiency virus long terminal repeat. J Gen Virol 1988;69:2913-2917.

54. Kretz-Remy C, Arrigo AP. The kinetics of HIV-1 long terminal repeat transcriptional activation resemble those of the hsp70 promoter in heat-shock treated Hela cells. FEBS Lett 1994;353:339-343.

55. Stanley SK, Bressler PB, Poli G and Fauci AS. Heat shock induction of HIV production from chronically infected promonocytic and T cell lines. J Immunol 1990; 145:1120-1126.

56. Brenner BG, Tao Y, Pearson E, Remer I, Wainberg MA. Altered constitutive and stress-regulated heat shock protein 27 expression in HIV type 1-infected cell lines. AIDS Res Hum Retroviruses 1995;11:713-717.

57. Hughes-Fulford M, McGrath MS, Hanks D, Erickson S, Pulliam L. Effects of dimethyl prostaglandin $A_{1}$ on herpes simplex virus and immunodeficiency virus replication. Antimicrob Agents Chemother 1992;36:22532258.

58. D'Onofrio C, Alvino E, Garaci E, Bonmassar E, Santoro MG. Selection of HTLV-1 positive clones is prevented by prostaglandin $\mathrm{A}$ in infected cord blood cultures. Brit J Cancer 1990;61:207-214.

59. Ankel H, Turriziani O, Antonelli G. Prostaglandin A inhibits replication of human immunodeficiency virus during acute infection. J Gen Virol 1991;72:2797-2800.
60. Rozera C, Carattoli A, De Marco A, Amici C, Giorgi C, Santoro MG. Inhibition of HIV-1 replication by cyclopentenone prostaglandins in acutely infected human cells. J Clin Invest 1996;97:1795-1803.

61. Rossi A, Elia G, Santoro MG. 2-Cyclopentenone, a new inducer of HSP70 with antiviral activity. J Biol Chem 1996;271:32192-32196.

62. Pennypacker G, Perelson AS, Nys N, Nelson G, Sessler DI. Localized or systemic in vivo heat inactivation of HIV: a mathematical analysis. J Acquir Immun Defic Syndr Hum Retrovirol 1995;8:321-329.

63. Brenner BG, Gryllis C, Wainberg MA. Role of antibodydependent cellular cytotoxicity and lymphokineactivated killer cells in AIDS and related diseases. J Leukoc Biol 1991;50:628-640.

64. Gryllis C, Wainberg MA, Bentwich Z, Gornitsky M, Brenner BG. Increased LAK activity against HIVinfected cell lines in HIV-1+ individuals. Clin Exp Immunol 1992;89:356-361.

65. Brenner BG, Gryllis C, Gornitsky M, Wainberg MA. Changes in natural immunity during the course of HIV-1 infection. Clin Exp Immunol 1993;93:142-148.

66. Gryllis G, Wainberg MA, Gornitsky M, Brenner B. Diminution of inducible lymphokine-activated killer cell activity in individuals with AIDS-related disorders. AIDS 1990;4:1205-1212.

67. Brenner BG, Dascal A, Margolese RG, Wainberg MA Natural killer cell function in patients with acquired immunodeficiency syndrome (AIDS) and HIV-1associated disorders. J Leukoc Biol 1989;46:75-83.

68. Brenner BG, Gornitsky M, Wainberg MA. IL-2 inducible natural immune (LAK) responses as a functional correlate of progression to AIDS. Clin Diag Lab Immunol 1994;1:538-544.

69. Earl PL, Moss B, Doms RW. Folding and interaction with GRP78-BiP, assembly, transport, of the HIV-1 envelope protein. J Virol 1991;65:2047-2055.

70. Otteken A, Moss B. Calreticulin interacts with newly synthesized human immunodeficiency virus type 1 envelope glycoprotein suggesting a chaperone function similar to that of calnexin. J Biol Chem 1996;271:97103.

71. Cullen BR, Heitman J. Chaperoning a pathogen. Nature 1994:372:359-360.

72. Thali M, Bukovsky A, Kondo E, et al. Functional association of cyclophilin A with HIV-1 virions. Nature 1994;372:363-365.

73. Franke EK, Yuan HEH, Luban J. Specific incorporation of cyclophilin into HIV-1 virions. Nature 1994;372:359 362.

74. Braaten D, Franke EK, Luban J. Cyclophilin A is required for an early step in the life cycle of human immunodeficiency virus type 1 before the initiation of reverse transcription. J Virol 1996;70:3551-3560.

75. Billich A, Hammerschmid F, Peichl P, et al. Mode of action of SDZ NIM 811, a non immunosuppressive cyclosporin A analog with activity against HIV type 1: interference with HIV protein-cyclophilin A interactions. J Virol 1995;69:2451-2461. 
76. Braaten D, Franke EK, Luban J. Cyclophilin A is required for the replication of group $M$ human immunodeficiency virus (HIV-1) and simian immunodeficiency virus SIV $_{\mathrm{CPZ}} \mathrm{GAB}$ but not the group O HIV-1 or other primate immunodeficiency viruses. J Virol 1996;70: $4220-4227$.

77. Yin L, Braaten D, Luban J. Human immunodeficiency virus type 1 replication is modulated by host cyclophilin A expression levels. J Virol 1998;72:6430-6436.

78. Aiken C. Mechanistic independence of Nef and cyclophilin A enhancement of human immunodeficiency virus type 1 infectivity. Virology 1998;24:139-147.

79. Endrich MM, Gehring H. The V3 loop of human immunodeficiency virus type- 1 envelope protein is a high- affinity ligand for immunophilins present in blood. Eur J Biochem 1998;252:441-446.

80. Sherry B, Zybarth G, Alfano M, et al. The role of cyclophilin A in the uptake of HIV-1 by macrophages. Proc Natl Acad Sci USA 1998;95:1758-1763.

81. Bartz SR, Pauza GD, Ivanyi J, Jindal S, Welch WJ, Malkovsky M. An hsp60 related protein is associated with purified HIV and SIV. J Med Primatol 1994;23: 151-154.

82. Nieland TJF, Tan MCAA, Monnee-van Muijen M, Koning $F$, Kruisbeek $M$, van Bleek GM. Isolation of an immunodominant peptide that is endogenously bound to stress protein GP96/GRP94. Proc Natl Acad Sci USA 1996;93:6135-6139. 


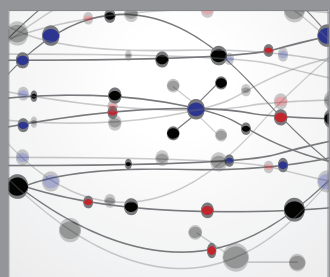

The Scientific World Journal
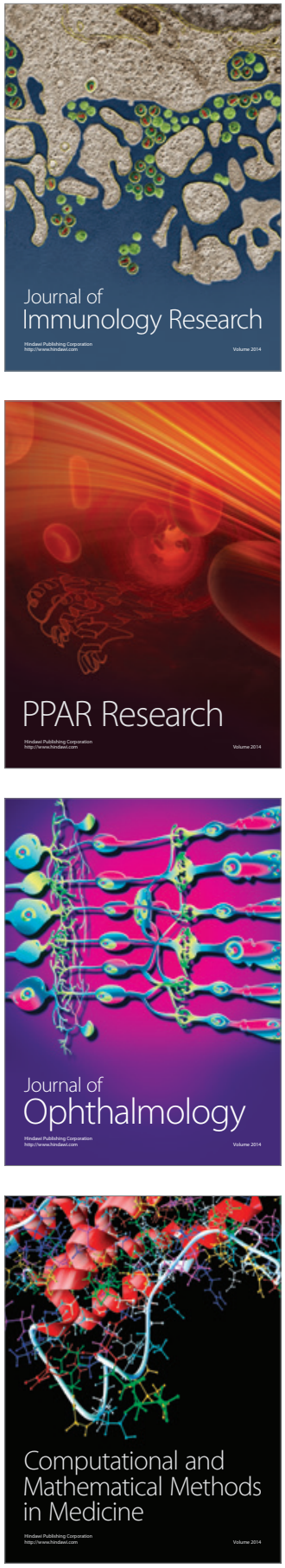

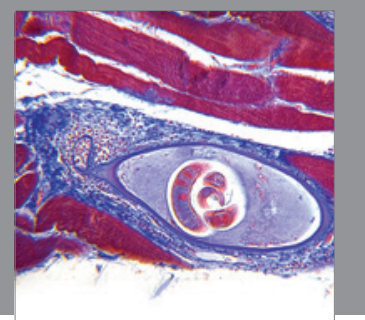

Gastroenterology

Research and Practice
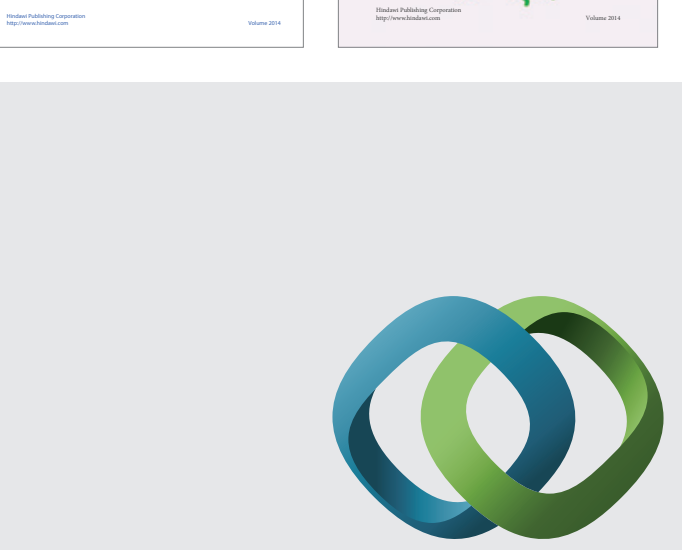

\section{Hindawi}

Submit your manuscripts at

http://www.hindawi.com
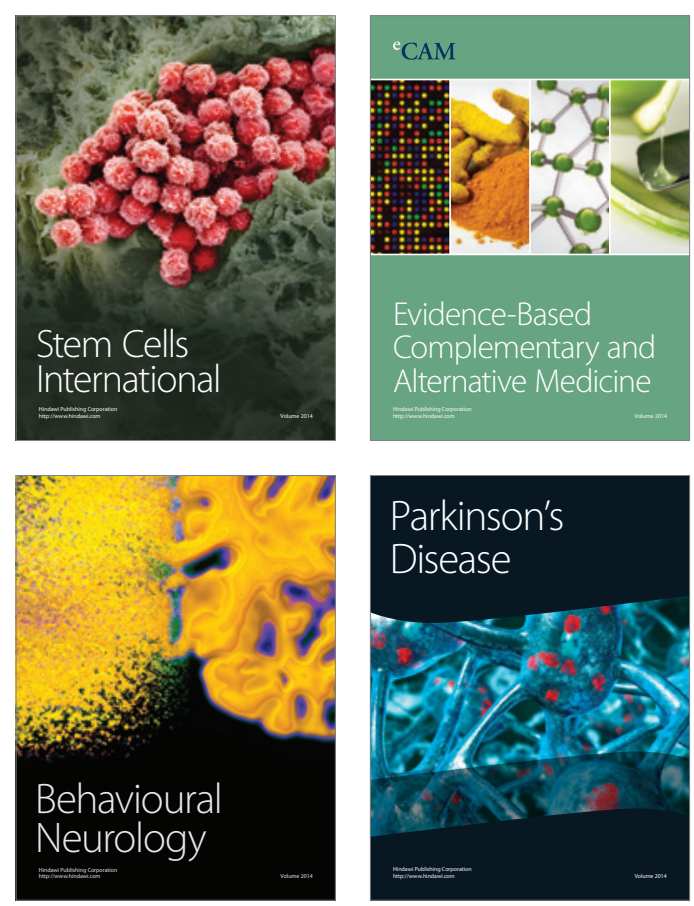

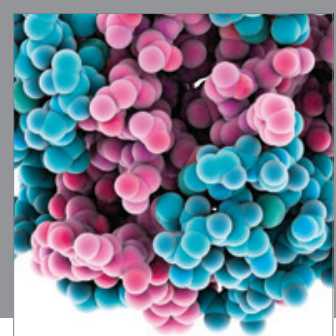

Journal of
Diabetes Research

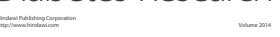

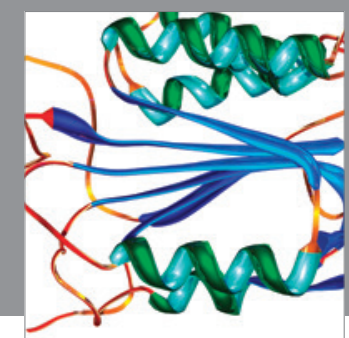

Disease Markers
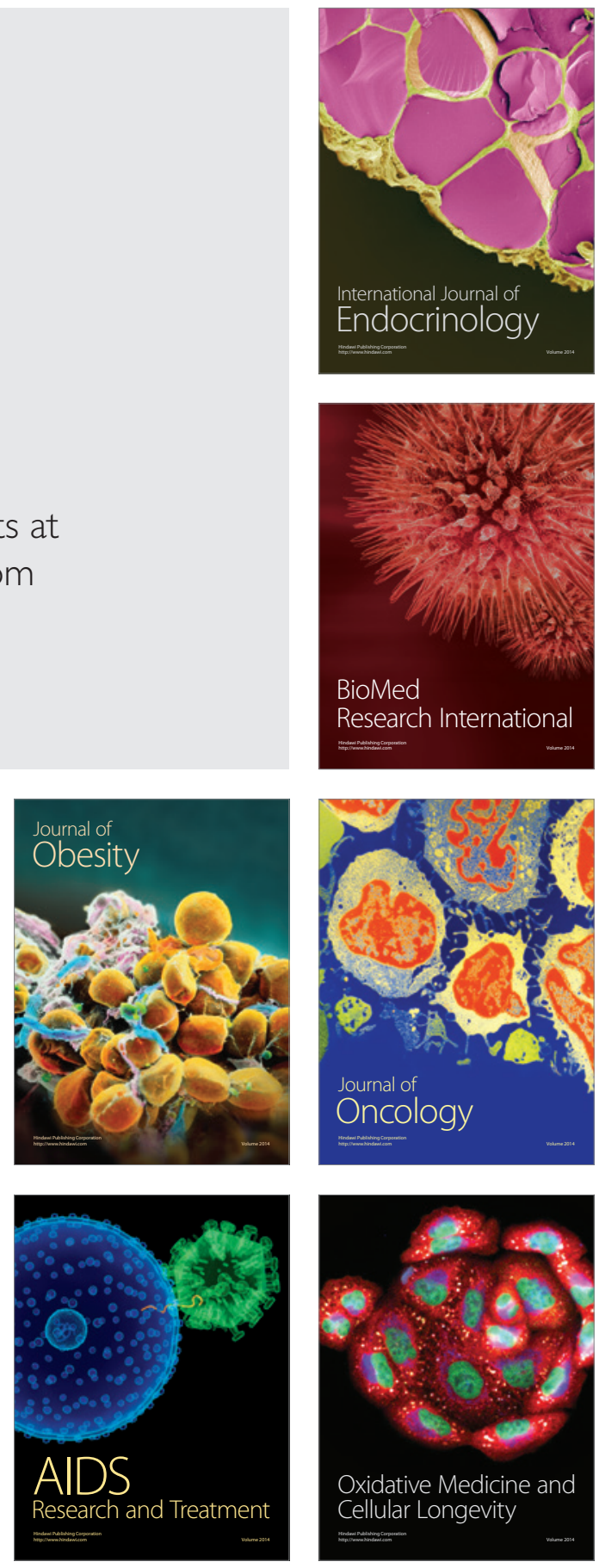